\section{Travellers' Health: How to Stay Healthy Abroad, 4th edition}

\author{
Richard Dawood, editor \\ Oxford University Press, Oxford, U.K., \\ 2002, ISBN: 0-19-262947-6, Pages: \\ 762, Price: $\$ 19.95$
}

Since the first edition of this book was published in 1986, travel medicine has flourished as a specialty, with seemingly no end to the expansion of air travel and the number of intrepid persons seeking out remote destinations for work or pleasure. The original edition was immediately received as the best general guide available for health professionals who dispense advice and medications to travelers, as well as for travelers who want more information about potential hazards they might encounter. This fourth edition, which is even more comprehensive and authoritative than its predecessors, continues the original successful formula and can be unreservedly recommended to anyone, expert or nonexpert, interested in the subject. Almost every conceivable topic is covered in the 75 chapters, each written by an expert or group of experts drawn mostly from the United Kingdom, with enough contributors from the United States to provide an international dimension.

One of the most useful sections, for travelers at higher risk, focuses on those who are pregnant, very young, elderly, and disabled, as well as those with HIV infection. Medical practitioners will find common topics addressed for patients with chronic, even life-threatening, conditions who ask about their fitness to travel and receive immunizations. Expedition health and medical kits are also well covered, and many chapters have references or guidance on accessing more information. A variety of sporting and recreational activities are discussed in individual chapters. Even humanitarian workers are considered with the inclusion of a chapter on land mines. Expatriates get a full discussion, including a warning not to habitually complain about their servants to expatriate col- leagues, as well as a valuable section on personal security. Otherwise, the text follows the familiar disease and disease vector chapter format with excellent clarity and conciseness.

Acceptable online services supply upto-date information for travelers on country-by-country health hazards, but none can compete with Dawood's guide. This gold mine of information is a fascinating read for even the armchair explorer. Travellers' Health is the authoritative guide for regular travelers, especially for anyone planning to live and work in foreign climes. For the health professional, the volume also serves as an accessible compendium of information about unfamiliar infectious diseases and environmental hazards and their prevention. And, despite the thoroughness of its content, the book has remained slim enough to pack away in the carry-on flight bag.

\section{Peter J. Baxter}

University of Cambridge, Cambridge, U.K.

Address for correspondence: Peter J. Baxter, University of Cambridge, Institute of Public Health, Robinson Way, Cambridge, CB2 2SR, United Kingdom; fax: 441223 336590; email: pjb21@medschl.cam.ac.uk

\section{Product Review: MicrobeCards}

\section{MicrobeCards, Mark S. Pepler, 103 cards, \$24.95, ISBN 1-5581-217-1, Washington, D.C., American Society for Microbiology Press, 2002.}

As someone whose professional life is split between teaching lay people to understand scientists and teaching scientists how to talk intelligibly to lay people, I am always looking for good teaching aids. Under the right conditions, MicrobeCards are definitely one such aid. MicrobeCards are a deck of 103 palm-sized $(6 \mathrm{~cm} \times 9 \mathrm{~cm})$, color-coded flash cards, which collectively provide a surprisingly large amount of accurate, well-organized information about five categories of microbes: gram-positive bacteria, gram-negative bacteria, viruses, fungi, and parasitic organisms.

All cards use the same format. The front is color-coded by microbe category and provides full-color microscopy and clinical images. The back features a schematic of the human body, showing, at a glance, where the microbe causes disease. It also displays a standardized summary of five key features: pathogenesis, immunity, epidemiology, diagnosis, and control. The microbe's name appears on front and back, and all labeled illustrations on the front are keyed to points in the summary on the back.

The strengths of this product are its portability, comprehensiveness, and decidedly low-tech approach to teaching. Small enough to slip into a shoulder bag, MicrobeCards are crammed with a textbook's worth of information. Having trouble waking up during the morning commute? Use the next traffic jam to test yourself on Streptococcus pyogenes - is the photo on the left acute impetigo or necrotizing fasciitis? Do you want to strike up a conversation with someone in line at the Burger Doodle but can't think of a way to break the ice? Simply reach in your bag, hand him or her flash card 97, and have your new acquaintance test you on the pathogenesis of Taenia saginata (answer: "a) Encysted larvae are ingested in undercooked beef. Cysticerci are released, attach to the small intestine by b) a hookless head and grow unto adult worms up to 10 meters long in 3 months. c) Each segment of the worm (proglottid) has male and female sexual organs and is capable of producing over 1,000 eggs. Proglottids are motile and can migrate - for example, from the anus at night."). The card describes this experience as "disconcerting."

For science students who would rather hang out in Java Monkey than the library, these low-tech flash cards just can't be beat. In fact, marketing the product as MicrobeCards, not MicrobePalmPilot, is a smart move. The detailed images, schematics, and linked text on MicrobeCards would be difficult to 